\title{
Isolation of Cellulosic Material from Outer Skin of Drumstick and Jarul Fruit and Their Derivatization
}

\author{
Tahsina Tasnim, Khadiza Akter, S. M. Mizanur Rahman* and M. Azizur Rahman* \\ Department of Chemistry, Dhaka University, Dhaka-1000, Bangladesh
}

(Received: 3 December 2015; Accepted: 5 April 2016)

\begin{abstract}
I. Introduction
Bangladesh is an agricultural country. So huge amount of agricultural as well as food wastes are coming from various agriculture activities and agro processed industries. These waste materials are one of the causes of environmental pollution and this creates problem of disposal. These agricultural wastes are mainly cellulosic materials which may be used as alternative sources of raw materials of different types of cellulosic derivatives such as nitrate, acetate, carboxymethyl cellulose (CMC) etc. as per demand. $\mathrm{CMC}$ and cellulose acetate are most widely used cellulosic derivatives. Sodium carboxymethyl cellulose (CMC) is a water soluble materials like salt and used in large scale without any refinement for use in detergents, drilling fluid and the paper industry while CMC is used as a food additive for their higher degrees of purity. Cellulose acetate is used as raw materials for the production of plastic films, transparent sheets, camera accessories, magnetic tapes, combs, telephone and electrical parts etc. So derivatization of cellulosic material of fruits skins might be economically significant and thus remove the waste disposal problem.
\end{abstract}

\section{Experimental}

Solvents and chemicals: All the solvents used in the present work were of analytical Grade (E. Merck and BDH) and were distilled before use.

\section{Materials and Methods}

\section{Sample collection and preparation}

The sample drumstick and jarul fruit were collected from different places of Dhaka city. The outer skin of drumstick and jarul fruit were separated cut into small pieces dried in open air and finally dried in the oven at $45^{\circ} \mathrm{C}$. After drying, the dried plant material was grinded with grinder mill and stored at room temperature to carry out all the experiments.

\section{Extraction of dried powder}

The dried powder of sample $40.0 \mathrm{~g}$ of each fruit was extracted separately with $(500 \mathrm{ml})$ petroleum ether (b.p. $40-60^{\circ} \mathrm{C}$ ) under reflux condition for 30 minutes. After refluxing, the content of the flask was allowed to cool at room temperature and filtered. The whole process was repeated twice and the residue was dried in the air and marked as "extractive free powder". The extractive and extractive free powders were found to be 4.4 and $95.6 \%$ for drumstick and that of 1.3 and $97.7 \%$ for jarul fruit, respectively.

\section{Delignification of extractive free powder}

The extractive free powders of the outer skin of drumstick and jarul fruit (39.5 and $34.5 \mathrm{~g}$, respectively) were

\footnotetext{
Author for correspondence. e-mail: smmrdb1981@yahoo.com
}

delignified as following the standard method ${ }^{1}$. The resultant delignified powders obtained were termed as "hollocellulose" and it was found to be 56.8 and $55.0 \%$, respectively.

Isolation of alpha-cellulose Holocellulose powder of outer skin of drumstick and jarul fruit (10.2g of each sample) were treated separately to separate alpha-cellulose as following the standard method ${ }^{2}$. The percentage of alphacellusoses was found to be 40.1 and $45.5 \%$, respectively.

\section{Preparation of cellulose acetate ${ }^{3}$}

Hollocellulose $3.1 \mathrm{~g}$ and $\alpha$-cellulose $1.5 \mathrm{~g}$ of both drumstick and jarul fruits sample were taken separately in a round bottomed flask and placed in a magnetic stirrer for frequent stirring at $80^{\circ} \mathrm{C}$ for about 1 hour. After stirring, it was placed in a water bath at $60^{\circ} \mathrm{C}$ and a mixture of acetic anhydride $(10 \mathrm{ml})$ and concentrated sulphuric acid $(0.4 \mathrm{ml})$ was added into it drop wise from a dropping funnel for about 30 minutes at constant temperature. After addition of the mixture, the content of the flask was kept in water bath for another 30 minutes at the same temperature $\left(60^{\circ} \mathrm{C}\right)$. The clear solution obtained at the bottom of the flask which was turned into curdy white precipitate after addition of distilled water. The precipitate of cellulose acetate obtained was centrifuged and washed with distilled water followed by ethanol. After air drying the yield of cellulose acetate and $\alpha$ cellulose of both the fruits were measured and it was found to be 38.8 and $40.1 \%$ for drumstick and 58.9 and $41.0 \%$ for jarul fruit, respectively.

\section{Preparation of carboxymethyl cellulose $e^{4}$}

Holocellulose $(0.7 \mathrm{~g}$ and $0.5 \mathrm{~g}$ of drumstick and jarul, respectively) and $\alpha$-cellulose $0.75 \mathrm{~g}$ of each fruit sample were taken separately in a round bottom flask and aqueous ethanolic $(80 \%)$ sodium hydroxide solution $(18 \%, 15 \mathrm{ml})$ was added with continuous stirring by a magnetic stirrer for 2 hours at $30^{\circ} \mathrm{C}$. The flask was placed in thermostatic water bath with a condenser at $58^{\circ} \mathrm{C}$, and then monochloroacetic acid $(10 \mathrm{ml}$ of $80 \%)$ was added drop wise through a dropping funnel with occasional stirring and then the content of the flask was refluxed for 6 hours with reflux condenser. The flask was removed from the bath, cooled to room temperature and the content was centrifuged. The centrifuged mass was washed with $80 \%$ ethanol and finally with a mixture of ethanol $(80 \%, 15 \mathrm{ml})$ and acetic acid $(1 \mathrm{ml})$. The carboxymethyl cellulose obtained was dried in air and the yield was calculated on the basis of holocellulose and $\alpha$-cellulose, respectively and it was found to be 84.7 and $67.6 \%$ for drumstick and 78.4 and $89.4 \%$ for jarul fruit, respectively. 


\section{Determination of degree of substitution (DS)}

Degree of substitution of the prepared acetate derivatives of holocelluluse and alpha-cellulose of both samples were determined by titrimetric method ${ }^{5}$. The degrees of substitution of these acetate derivatives of holocellulose and alpha-cellulose were calculated using the following equation.

$$
\% \mathrm{AG}=\frac{\left[\left(V_{b_{i}}+V_{b_{t}}\right) \mu_{b}-V_{a} \times \mu_{a}\right] 43 \times 100}{m_{c a}}
$$

Spectroscopic Study of holocellulose, a-cellulose, cellulose acetate, and carboxymethyl cellulose

The IR spectra of holocellulose, alpha-cellulose, the derivatives of the acetate and carboxylmethyl cellulose of the outer skin of drumstick and jarul fruit were recorded separately in $\mathrm{KBr}$ pellets using a Shimadzu IR-470 spectrophotometer. Characteristics absorption peaks for holocellulose, alphacellulose and the derivatives of their acetate and carboxymethyl cellulose were identified and the absorption pattern was discussed in the following section.

\section{Results and Discussion}

The drumstick and jarul fruit were collected locally; skin of drumstick was separated. The outer skin of the drumstick and jarul fruit were cut into small pieces dried and powdered. The powders were separately extracted with petroleum ether. The extractive free powders were separately delignified. Alphacelluloses were separated from the delignified powders. Each of the holocellulose and alpha-cellulose were separately acetylated and carboxy methylated. Degrees of substitution of the acetate derivatives were determined and IR spectral study of the holocellulose and alpha-cellulose and the derivatives of their acetate and carboxymethyl cellulose were carried out. The amount of petroleum ether (b.p. $40-60^{\circ} \mathrm{C}$ ) extract in the outer skin of drumstick $(4.43 \%)$ and in jarul fruit $(1.26 \%)$, was found to be low; this indicates that these materials contain very small amounts of soluble organic materials. It was observed that the holocellulose in the outer skin of drumstick is $56.84 \%$ and the same in the jarul fruit is $55.05 \%$. The corresponding alpha-celluloses are $40.10 \%$ and $45.46 \%$ in the outer skin of drumstick and in jarul fruit, respectively. This result reveal that, both the outer skin of drumstick and jarul fruit may be used as the sources of cellulosic materials, which are comparable to the other agro waste materials $\mathrm{s}^{6,7,8}$. The degree of substitution of the acetate derivatives of the holocellulose and the corresponding alpha-cellulose are $18.58 \%$ and $2.06 \%$ for the outer skin of drumstick and it was $18.34 \%$ and $5.33 \%$ for the outer skin of jarul fruit, respectively. These results reveal that the cellulosic materials obtained from both these two sources have been partially acetylated. Infrared spectral analysis of the holocellulose shows peaks at 3450-3400, 3000-2850 and $1100-1000 \mathrm{~cm}^{-1}$ indicating the presence of $\mathrm{O}-\mathrm{H}$ stretching, $\mathrm{C}-\mathrm{H}$ stretching and $\mathrm{C}-\mathrm{O}$ stretching of sugar unit, respectively, but no distinct peak for $\mathrm{C}=\mathrm{O}$ stretching was obtained.

On the other hand, IR spectra of acetate derivatives of holocellulose in both the cases indicated the strong absorption peak of $>\mathrm{C}=\mathrm{O}$ for acetate group at around $1730-1747 \mathrm{~cm}^{-1}$ and the absorption peak of $\mathrm{C}-\mathrm{O}$ stretching of acetyl group at 1230 $1239 \mathrm{~cm}^{-1}$. The other characteristic peaks due to $\mathrm{C}-\mathrm{O}$ stretching of skeletal backbone were observed in both holocellulose and its acetate derivative at $1020-1060 \mathrm{~cm}^{-1}$. The characteristic strong peaks of $\mathrm{O}-\mathrm{H}$ stretching for both holocellulose and their acetate derivatives indicate that the inner portion has many free- $\mathrm{OH}$ groups left in acetate derivatives. This finding suggests the materials have been partially acetylated.

The IR spectral analysis of alpha-cellulose and its acetate derivatives possess the strong absorption bands at around 3437$3474 \mathrm{~cm}^{-1}$, due to the presence of large number of $-\mathrm{OH}$ groups in the fractions. The acetate derivative possess the distinct strong absorption band for $>\mathrm{C}=\mathrm{O}$ group at around 1756-1763 $\mathrm{cm}^{-1}$ with the other characteristic peak of $\mathrm{C}-\mathrm{O}$ stretching of skeletal backbone at $1050-1101 \mathrm{~cm}^{-1}$. The $\mathrm{C}-\mathrm{H}$ stretching band of acetate derivatives of holocellulose and alpha-cellulose was observed with strong intensity at 2925, 2940 and $2945 \mathrm{~cm}^{-1}$, except the acetate derivative of $\alpha$-cellulose in case of jarul fruit.

The IR spectral analysis of the carboxylmethyl cellulose derivatives of holocellulose and alpha-cellulose shows the strong absorption bands at 1618, 1619, 1624 and $1650 \mathrm{~cm}^{-1}$ due to the asymmetric stretching and that of 1410, 1421, 1434 and $1436 \mathrm{~cm}^{-1}$ for symmetric stretching of the carboxylate ion that present in the CMC derivatives of holocellulose and alphacellulose, respectively. The presence of these peaks is also giving the information of successful derivatization of these two fractions. The $\mathrm{C}-\mathrm{H}$ stretching band of carboxymethyl cellulose derivatives was observed with moderate intensity at 2924-2931 $\mathrm{cm}^{-1}$. The DS and IR spectral analysis show the successful partial acetylation of the cellulosic materials obtained from the outer skin of drumstick and jarul fruit.

\section{Conclusion}

This finding suggests that agro-wastes (outer skin of drumstick and jarul fruit) might be used as source of cellulosic material and the cellulosic material of the agro waste could be successfully and significantly converted into their derivatives (cellulose acetate and carboxymethyl cellulose), which can be used for different commercial and industrial purposes.

\section{References}

1. Rowell RM, 2005. Handbook of Wood Chemistry and Wood Composite, CRC Press, 62.

2. Brady GS, 1971. Alpha cellulose, Materials Handbook, McGrawHill Book Co., New York, 169.

3. Israel AU, IB., Obot SA, Umoren V. Mkpenie and JE, Asuquo 2008. Production of cellulosic polymers from agriculture wastes, E-J. of Chem., 5(1): 81-85.

4. Khundkar MH. and AK, Bhattacharjee 1964. Derivatisation of carboxymethyl cellulose, Pak. J. Sci. Ind. Res., 8: 89.

5. Filho GR, DS, Monteiro CDS, Meirele Assuncao RMND, DA, Cerqueira HS,. Barud Rebeiro SJL and Messade Y., 2008. Synthesis and characterization of cellulose acetate produced from recycled newspaper. Carbohy. Poly., 73(1): 74-82.

6. Rahman MA, T. Muslim and MR, Islam 2012. Investigation on Orange peel: Derivatisation of isolated cellulosic materials and analysis of the fatty acid composition. Dhaka Univ. J. Sci., 60 (1): 77-78.

7. Rahman MA, T, Muslim A, Saha S, Akther F, Rashid MR, Afrin Akter N, and Debnath S, 2014. Isolation of cellulosic material from agro-waste and its derivatization. Int. J. of Adv. in Phar. Biol. And Chem., 3(2): 2277- 4688.

8. Hossain I, S, Mostofa U, Muslima F, Akter T, Akter A, Saha S, Debnath, T, Muslim and MA Rahman, 2015. Isolation of cellulosic materials from agro-wastes and their derivatization. Dhaka Univ. J. Sci., 63(1): 43-46. 
